\title{
UMA BREVE REVISÃO HISTÓRICA DO PAPEL DAS VIDEOAULAS NA EaD NO BRASIL
}

\author{
A BRIEF HISTORICAL REVIEW OVER THE ROLE OF VIDEO CLASSES IN \\ DISTANCE EDUCATION IN BRAZIL
}

Ana Paula Kuczmynda da Silveira Instituto Federal de Educação, Ciência e Tecnologia de Santa Catarina

Aline Cassol Daga Programa de Pós-graduação em linguística - UFSC

Michelle Donizeth Euzébio Programa de Pós-graduação em linguística - UFSC Josias Hack Universidade Federal de Santa Catarina

Simone Lesnhak Krüger Universidade da Região de Joinville

\begin{abstract}
Resumo
Este artigo tem como objetivo refletir sobre o papel que tem ocupado a produção e veiculação de videoaulas dentro do panorama da Educação a Distância no Brasil, principalmente no contexto de programas nacionais destinados à educação de jovens e adultos, tanto no que concerne à formação discente, quanto no que concerne à formação continuada de professores em atuação nas redes públicas de ensino. Para tanto, o artigo se divide em duas seções: na primeira seção revisitamos a trajetória do programa Telecurso em suas três versões - Telecurso $2^{\circ}$ grau e Telecurso $1^{\circ}$ Grau, Telecurso 2000, Novo Telecurso; na segunda seção discutimos os programas de EaD vinculados à formação do professor em serviço.
\end{abstract}

Palavras-chave: Educação a Distância. Videoaula. Programas de formação de jovens e adultos. Formação continuada de professores.

\begin{abstract}
This article aims to reflect on the role that has occupied the production and placement of video lessons within the panorama of distance education in Brazil, especially in the context of national programs for youth and adults, both with regard to training students, as with regard to the continuing education of teachers in action in public schools. In order to do that, the article is divided into two section: in the first section we revisit the history of the program Telecourse in its three versions - Telecurso 2o grau and Telecurso 10 grau, Telecurso 2000 and Novo Telecurso; in the second section we discuss the educational programs connected to the distance training of teachers in service.
\end{abstract}

Key-words: Distance Education. Video classes. Education programs for youth and adults. Continuing education for teachers. 


\section{INTRODUÇÃO}

O conhecimento e a aprendizagem, ao que parece, nunca foram tão valorizados como nos anos mais recentes. As sociedades contemporâneas, marcadas pelas transformações tecnológicas, exigem respostas cada vez mais rápidas e habilidades múltiplas dos profissionais, os quais necessitam de qualificação e aprimoramento constantes.

Moran (2009) aponta que as atividades a distância vêm se configurando como essenciais nos contextos atuais de educação, de forma a atender a demandas diferenciadas de uma sociedade cuja complexidade vem crescendo pronunciadamente. Aponta, ainda, que em sendo uma modalidade de educação, a Educação a Distância (EaD) tem um compromisso com a qualidade.

Pretto (2001) coaduna com essa necessidade de atenção à qualidade na $\mathrm{EaD}$ e realça a importância da modalidade no contexto atual, principalmente devido ao fato de poder "contribuir com o debate sobre a redução tanto da desigualdade, como das distâncias entre as diversas esferas e sistemas de educação, particularmente na esfera da educação pública em nosso país" (PRETTO, 2001, p. 36). Nesse mesmo sentido, os Parâmetros Curriculares Nacionais (PCNs), desde 1997, realçam a importância de se preparar o aluno para o mundo do trabalho e para constituir um cidadão crítico capaz de intervir positivamente na sociedade na qual interage, isso significa reavaliar mesmo as concepções que temos de professor, de escola e de educação. Para Pretto, isso significa ressignificar o espaço escolar, entendendo-o como "um espaço aberto de interações não lineares" (PRETTO, 2001, p. 44).

Além disso, os documentos oficiais de ensino, em especial os PCN (BRASIL, 1997) anunciam a necessidade de formação do professor em serviço. Também nesse sentido, como sinaliza Toschi (2001), a EaD tem sido apresentada como uma modalidade de ensino favorável para minimizar os problemas relativos à formação continuada de professores.

O momento atual se anuncia, então, como singular: de um lado as exigências de uma sociedade crescentemente grafocêntrica e a cada dia mais complexa; de outro lado, as limitações de um sistema escolar que implica a necessidade de se repensar a própria escola, o professor e as fronteiras do espaço escolar, bem como a novidade que ainda representa o uso das Tecnologias de Informação e Comunicação (TIC) vinculadas a programas de $\mathrm{EaD}$ que se multiplicam fora e dentro do país. Nesse panorama extremamente diverso, o papel da educação inicial e continuada configura-se redimensionado e, em muitos casos, mediado por recursos tecnológicos que possam estabelecer uma ponte entre professor e aluno. Nas iniciativas públicas e privadas, materializadas em programas de educação de jovens e adultos a distância, bem como em programas de formação continuada de professores, ressalta-se o papel que vem sendo ocupado, desde meados da década de 1970, pelas videoaulas.

Nesse contexto, é objetivo deste artigo refletir sobre os programas de educação de jovens e adultos a distância, bem como sobre os programas de formação continuada de professores no Brasil. Neste último caso, o nosso foco se volta, mais especificamente, à formação continuada do professor de Língua Portuguesa. A partir de tais reflexões, deseja-se pensar o papel que vêm ocupando as videoaulas na EaD brasileira. Para tanto, este artigo divide-se em duas seções: na primeira seção revisitamos a trajetória do 
programa Telecurso em suas três versões - Telecurso $2^{\circ}$ grau e Telecurso $1^{\circ} \mathrm{Grau}$, Telecurso 2000, Novo Telecurso; na segunda seção discutimos os programas de EaD vinculados à formação do professor de Língua Portuguesa em serviço.

\section{A TRAJETÓRIA DO TELECURSO: O ENSINO MEDIADO POR VIDEOAULAS}

Por educação a distância, de maneira geral, entendemos um sistema que visa a levar a educação ${ }^{1}$ a uma população geograficamente dispersa, por meio de uma relação nãopresente, no entanto, mais do que potencializar o acesso à educação, a EaD é importante como instrumento de qualificação com os seguintes traços diferenciadores, os quais podem ser observados nas mais diversas definições de educação a distância: separação professor-aluno; utilização sistemática de meios e recursos tecnológicos; aprendizagem individual; apoio de uma organização de caráter tutorial; comunicação bidirecional. Para compreender a natureza multidimensional dessa área, Moore $(2008$, p. 2) adota a seguinte definição:

Educação a distância é o aprendizado planejado que ocorre normalmente em um lugar diferente do local de ensino, exigindo técnicas especiais de criação do curso e de instrução, comunicação por meio de várias tecnologias e disposições organizacionais e administrativas especiais.

A EaD obteve grande impulso, no Brasil, a partir da década de 1990. As inovações das TIC e a expansão do ensino superior foram determinantes para esse fenômeno. Nessa mesma década, a EaD foi reconhecida formalmente, sendo explicitamente tratada na Lei n. ${ }^{\circ}$ 9.394, de 20 de dezembro de 1996, denominada LDBEN (Lei de Diretrizes e Bases da Educação Nacional), nas Disposições Gerais, art. 80, no qual se aponta que: "O Poder Público incentivará o desenvolvimento e a veiculação de programas de ensino a distância, em todos os níveis e modalidades de ensino, e de educação continuada”.

No contexto da $\mathrm{EaD}$, a partir da popularização da televisão e da teledramaturgia, a interação com o professor tradicionalmente se efetivou por meio de materiais impressos e videoaulas, recursos estes aos quais, mais recentemente, somaram-se as teleaulas. No que diz respeito à diferença entre teleaula e videoaula, adotaremos neste artigo a conceituação estabelecida por Moran (2009). O autor entende teleaula como aquela aula realizada a distância na qual o professor é visto pelos alunos ao vivo, em tempo real, e videoaula como a aula gravada à qual posteriormente o aluno tem acesso.

Moran (2009) assinala que, nos dias atuais, as videoaulas são produzidas em estúdio e posteriormente assistidas pelos alunos, quer em grupos, quer individualmente, em salas especialmente destinadas a esse fim ou a partir de outro qualquer local em que haja equipamento para tanto, com o acompanhamento de um professor orientador/tutor ou não, de forma semipresencial ou online.

\footnotetext{
${ }^{1}$ Optamos por educação ao invés de ensino pois acreditamos que a educação extrapola o campo delimitado pelo binômio ensino e aprendizagem, situando-se na amplitude maior da prática social, apesar de o ensino ser, sem dúvida, um dos fatores que contribui para a educação.
} 
O autor ainda aponta que o modelo de salas onde os alunos contam com a supervisão de um tutor, o qual supervisiona a exibição do vídeo e as atividades relativas aos conteúdos das diversas disciplinas que compõem o curso, parece ser bastante comum. Todavia, atualmente há ainda a possibilidade de que os alunos acessem as videoaulas de casa ou do trabalho através da WEB, ou a partir da aquisição de CD ou DVD com o conteúdo das videoaulas. Nesse caso, o aluno comparece opcionalmente a um polo para receber orientações que julgue necessárias e para realizar as atividades avaliativas.

Moran (2009) aponta que os modelos de EaD em que os alunos são organizados em turmas de recepção para assistir às videoaulas e posteriormente realizar atividades em grupo ou individualmente, reproduzem o modelo presencial de classe, contribuindo para criar vínculos sociais e afetivos, que parecem favorecer a permanência do sujeito no programa de EaD. Entendemos que esse modelo potencializa as trocas entre os alunos, fortalecendo a dimensão interindividual e agencia a emergência, nos alunos, de um sentimento de pertencimento a um grupo/programa de EaD.

A popularização das videoaulas no Brasil parece estar profundamente atrelada à trajetória traçada pelos telecursos, desde experiências remotas até os dias de hoje, Trajetória essa sobre a qual refletiremos ao longo desta seção.

Segundo Maciel (2008b), em 1961, o primeiro programa de alfabetização utilizando a televisão foi elaborado pela professora Alfredina de Paiva e Souza. No ano seguinte, também utilizando a televisão, aliada a material impresso, foi criado o projeto Universidade de Cultura Popular, o qual foi idealizado por Gilson Amado e Manoel Jairo Bezerra para preparar jovens e adultos para a realização das provas do exame supletivo do antigo primeiro grau (os Exames de madureza). As aulas eram produzidas na TV Tupi e rede de emissoras associadas com o patrocínio da Shell.

Também na década de 1960, foi implantado o primeiro canal de televisão educativa: a Televisão Universitária do Recife - canal 11, sob a administração da Universidade Federal de Pernambuco. A Fundação Centro Brasileiro de Televisão Educativa (FCTVE), apesar de ter surgido em 1967, foi inicialmente apenas um centro produtor de programas educativos; só em 1973 ela recebeu a outorga do canal, passando a ser denominada Televisão Educativa (TVE), canal 2 no Rio de Janeiro (MACIEL, 2008b).

No início da década de 1970, entre 1972 e 1973, foi produzido pela FCTVE o primeiro curso supletivo de teleducação do Brasil, o Curso Supletivo "João da Silva", que tinha o formato de telenovela e visava ao ensino do conteúdo das quatro primeiras séries do então primeiro grau (MACIEL, 2008a). O projeto era arrojado para a época e ressignificava o conceito de aula tradicional. A caracterização do personagem principal, João da Silva, interpretado pelo ator Nelson Xavier, remetia ao aluno típico do programa, o aluno adulto de baixa renda, proveniente de municípios do interior do Brasil, que foi tentar a vida nas grandes cidades e se evadiu precocemente da escola. Notamos, aqui, a tentativa por parte do projeto, de criar uma identificação entre o aluno e o personagem com o objetivo de conquistar a sua adesão ao curso, uma vez que a caracterização do personagem e de seu entorno promovem um efeito de aproximação da realidade vivenciada pelo aluno. Ainda, é preciso lembrar que o modelo de telenovela remetia a um formato de programa de TV que vinha conquistando cada vez mais espaço na televisão naquele momento. 
A recepção das videoaulas, que já então despontavam como uma importante ferramenta de EaD, podia ocorrer nos dois modelos apontados por Moran (2009): ou os alunos assistiam às aulas nos telepostos com orientação de monitores, ou em sua residência; neste último caso, os alunos buscavam assistência, se julgassem necessário, em núcleos de atendimento chamados Centros Controladores.

O Curso Supletivo "João da Silva" foi sucedido pelo Curso Supletivo "A Conquista", que utilizou o mesmo formato de EaD do primeiro curso, baseado em material impresso e videoaulas produzidas em forma de telenovela a cores. Segundo Maciel (2008a), "A conquista" foi a primeira telenovela educativa brasileira produzida em cores. Segundo a FCBTVE (1979, apud Maciel, 2008a, p.5), "Os 200 capítulos de TV do Projeto Conquista encontram-se organizados da seguinte forma: 4 programas preliminares; 148 capítulos instrucionais (novela/aula); 1 capítulo sem conteúdo instrucional; 37 retrospectivas; 10 programas complementares".

Em 16 de janeiro de 1978 foi lançado, primeiramente em São Paulo e posteriormente no resto do país, como resultado de uma parceria entre a Fundação Padre Anchieta (TV Cultura/SP) e a Fundação Roberto Marinho, o Telecurso $2^{\circ}$ grau (MOREIRA, 2006). O programa, assim como outros programas anteriores, baseava-se em videoaulas e fascículos impressos, com o objetivo de preparar os alunos para o exame supletivo. $\mathrm{O}$ programa representou a primeira incursão de uma televisão comercial no campo da $\mathrm{EaD}$.

É importante entender que apesar de a iniciativa de criação e veiculação do Telecurso $2^{\circ}$ grau e, posteriormente, do Telecurso $1^{\circ}$ grau, ter se dado a partir da mobilização da Fundação Roberto Marinho, os programas não surgiram dissociados de um projeto educacional do governo militar. De fato, a própria TV Globo, como aponta Moreira (2006), foi, por muitos, entendida como porta-voz do governo militar durante a ditadura. Havia, naquela época, a necessidade urgente de capacitação de mão de obra para ocupar postos nas indústrias, então, em franco desenvolvimento. Essa capacitação se ocorresse de forma presencial, seria extremamente custosa ao governo. O mesmo governo já vinha apostando no ensino tecnicista com o mesmo objetivo, porém, a EaD cumpria um papel um pouco diferente daquele cumprido pelas muitas escolas técnicas então espalhadas pelo país: resolver o problema da formação do profissional da indústria, sem que ele, no entanto, tivesse que se deslocar do seu local de trabalho para fazê-lo.

Segundo Moreira (2008, p. 57) três características básicas marcavam o sistema Telecurso desde o início:

1. Articulação de uma grande rede de emissoras de televisão que exibiam as aulas de forma simultânea;

2. Edição de fascículos semanais, vendidos em quase três mil municípios em todas as partes do Brasil e a preço acessível;

3. Divulgação sistemática de: datas para a inscrição em exames supletivos, data da chegada dos fascículos às bancas e programação com os horários em que as emissoras passariam as teleaulas. 
Ainda, apesar de as videoaulas produzidas para o Telecurso $2^{\circ}$. Grau e posteriormente para o Telecurso $1^{\circ}$. Grau oscilarem entre o modelo de aula tradicional, e um modelo de aula que se aproximava do documentário, elas eram produzidas por uma equipe técnica de elevada qualidade, vinculada à produção televisiva, com profissionais contratados junto ao mercado com recursos das Organizações Globo, ou cedidos do próprio quadro da empresa. À Fundação Padre Anchieta cabia a formulação do material didático e as pesquisas necessárias para a constituição dos programas. Todavia, como aponta Moreira (2008, p. 49), não havia uma efetiva integração entre a equipe de professores da Fundação Padre Anchieta e a equipe de profissionais da televisão da Fundação Roberto Marinho, já que os primeiros não participavam da produção do programa, o que implicava um "distanciamento entre o conteúdo idealizado pelos professoreseducadores e o produto final" efetivamente veiculado. Ou seja, as videoaulas produzidas refletiam uma preocupação centralizada, por parte da Fundação Roberto Marinho, nas técnicas e qualidade de produção televisiva, em detrimento dos aspectos didáticos propriamente ditos. Isso emprestava também à TV Globo, um papel de censor sobre o material formulado pelos professores da Fundação Padre Anchieta e, uma vez que a escolha dos conteúdos para a confecção do material didático excluiu da pesquisa para a composição do currículo, a maioria dos Estados, favorecia a massificação e a padronização do ensino.

A partir de 1994 e até 1995, quando entrou no ar o Telecurso 2000, o programa Telecurso passou por uma reorganização de forma a contemplar as novas necessidades no mundo do trabalho, as expectativas de um novo parceiro no projeto - a FIESP -, e de maneira a incorporar ao projeto, tecnologias mais modernas de produção de videoaulas, as quais foram aos poucos migrando do modelo inicialmente veiculado para, um modelo que privilegiava a teledramaturgia. Nesse sentido, o Telecurso 2000 se aproximou do Programa "João da Silva", apostando em uma metodologia de ensino que partia da discussão de situações do dia a dia, para abordar os conteúdos do programa. Apesar de as videoaulas apresentarem os mediadores dessa interação entre o conhecimento e o aluno caracterizados como personagens em interação cotidiana, sempre um personagem assumia de uma forma ou e outra, a voz do professor (ainda que não caracterizado como tal), daquele que explica os conteúdos, que instrui, que transmite conhecimentos.

Além do alcance nacional, o Telecurso 2000 representou a exportação dessa proposta de EaD para Portugal, Angola, Moçambique e Cabo Verde; para o Japão, em que o programa é utilizado em cursos de Língua Portuguesa voltados ao Mercosul e para a Inglaterra, onde o programa foi adaptado para ser utilizado na rede pública de ensino para que os alunos adquirissem conhecimentos sobre o Brasil. Ainda, o programa foi adotado como supletivo oficial em diversos estados brasileiros (BARROS, 2003).

É interessante apontar que os objetivos do Telecurso 2000 parecem alinhar-se àqueles traçados em 1990 na Conferência Mundial de Educação Para Todos - Jontien Tailândia (UNESCO, UNICEF, BIRD, PNUD) que apontavam a educação como base para uma sociedade igualitária, solidária e integrada e também aos delineados no Plano Decenal de Educação para Todos (1993) que dá ênfase à educação a distância na ampliação dos meios de educação básica disseminados pelos meios de informação, comunicação e ação, em apoio às redes escolares locais, incluindo programas de educação aberta e a distância, centros de difusão cultural, bibliotecas, núcleos multimeios e espaços de ação comunitária. 
Moreira (2006) aponta que uma das razões que levaram à reformulação do Telecurso diz respeito aos resultados potencialmente ruins alcançados pelo Telecurso $2^{\circ}$ Grau. Segundo o autor, em nenhuma das três submodalidades existentes (recepção organizada - nos telepostos - controlada ou livre), utilizando a metodologia e o material didático do Telecurso como meio principal ou subsidiário, o programa alcançou a meta de preparar os alunos, no conjunto das disciplinas, para os exames supletivos. Isso fez com que o programa e a metodologia de planejamento das videoaulas fossem reavaliados, de forma a se buscar uma maior aproximação dos alunos, através de aulas mais envolventes, que buscassem atribuir sentidos a questões do dia a dia e partissem de conteúdos mais concretos, mais próximos da realidade desses mesmos alunos, para que depois se buscasse um certo nível de abstração.

Ainda segundo Moreira (2006), o Telecurso 2000 se voltava a 4 perfis de trabalhadores: desempregados, em risco de desocupação, cooperados ou autônomos e empreendedores. Uma vez que o projeto era resultado de uma parceria com o empresariado, esse mesmo empresariado se encarregou de montar telessalas para acomodar seus funcionários e/ou associados, o que acabou, muitas vezes, funcionando como um fator coesivo. Além disso, o programa realçou a importância dos tutores presenciais, que receberam capacitação para mediar o trabalho com os módulos e vídeos.

As questões levantadas por Moreira (2006) em relação ao Telecurso, sinalizam na direção da compreensão de que um projeto de $\mathrm{EaD}$ não pode ser entendido apenas como um projeto de transmissão de conhecimento em que cabe ao aluno articular o próprio aprendizado. Muito pelo contrário, se por um lado, a EaD possibilita ao aluno um maior espaço para fazer escolhas, por outro lado, ela não pode descuidar de uma articulação entre os diferentes recursos que mobiliza, para que esses possam fazer sentido para o aluno, proporcionando uma mediação válida (seja de maneira semipresencial ou a distância) em relação ao conhecimento a ser construído, levando, assim, à aprendizagem. Como aponta Vigotski (2008), só aprendemos aquilo que é significativo aos nossos próprios olhos, aquilo a que conseguimos atribuir sentido.

A despeito das mudanças efetivadas, os resultados apresentados por Moreira (2006) ainda sinalizam a ineficiência do programa no que tange à aprovação dos cursistas nos exames supletivos (da ordem de 44,5\%). Por outro lado, Barros (2003) entende que o Telecurso 2000 representou um progresso significativo no que tange à $\mathrm{EaD}$, adequandose ao perfil dos alunos e aos objetivos que eles manifestavam. Porém, tanto Moreira (2006), quanto Barros (2003) sinalizam na direção de que é a falta de espaço para o aluno expressar-se, a falta de diálogo entre professor e aluno, a falta de flexibilidade do método, os maiores obstáculos apresentados pelo programa.

Com o objetivo de minorar essa ausência de diálogo, surgiu, em 2006, o Novo Telecurso, que integra as videoaulas e o material apostilado a uma rede de serviços multimídia que podem ser acessados através da página virtual do programa e que conecta alunos e professores através do país. Ainda é cedo para avaliar os resultados do programa, porém sua reformulação parece sinalizar a intenção de dar voz aos alunos, professores e tutores que dele fazem parte, o que aponta na direção de uma $\mathrm{EaD}$ mais crítica e possivelmente mais reflexiva. No caso específico da disciplina de Língua Portuguesa, todavia, alguns impasses persistem. Dentre eles, um parece especialmente importante: a dificuldade em articular, em um programa de EaD com essas 
características, atividades de leitura/escuta, produção de texto e análise linguística, fazendo com que o aluno posicione-se criticamente perante o próprio texto, retomandoo, refletindo sobre ele, reescrevendo-o. Some-se a isso a dificuldade de contemplar as demandas de cada grupo específico, promovendo eventos de letramento que façam sentido em cada realidade em particular.

As questões que emergem ao se pensar programas com a amplitude do Telecurso no que tange ao ensino e aprendizagem de Língua Portuguesa não são muito diversas daquelas que despontam quando se pensa a formação continuada de professores via televisão e videoaula. E as motivações que levaram à proliferação de uma e de outra prática, como veremos ao longo da próxima seção, também não são muito diferentes.

\section{A FORMAÇÃO DE PROFESSORES POR TELEVISÃO E VIDEOAULA}

Como já apontamos anteriormente, a aprendizagem por EaD via televisão teve seu início na década de 60; a partir da década de 90, proliferaram programas que visavam a facilitar a formação de professores, proporcionando, segundo o Plano Nacional de Educação (PNE), Lei n. ${ }^{\circ}$ 9.394/96, a abertura de novos horizontes de atuação profissional, no sentido de despertar reflexão sobre a prática educacional e busca de seu aperfeiçoamento técnico, ético e político. Eis os programas de que se têm registro.

No ano de 1991, a TVE Brasil inaugurou a formação de professores por videoaulas com o Programa Salto para o Futuro (MEC, 2009). Este programa teve início como projeto piloto chamado "Jornal da Educação - Edição do Professor", concebido e produzido pela Fundação Roquette Pinto, hoje Associação de Comunicação Educativa Roquette Pinto (ACERP) e o público-alvo eram os professores do ensino fundamental e médio, atendendo também a temas de interesse para a educação infantil. Seus objetivos se voltavam à capacitação, atualização e aperfeiçoamento de professores da rede pública e à implementação de ações que promovessem a mudança da prática pedagógica, a partir da reflexão sobre as mudanças sociais, tecnológicas e suas implicações na educação, gerando a necessidade de formação ao longo da vida. Para a recepção organizada do programa, foram implementados, pelas Secretarias de Educação, desde 1991, os telepostos/telessalas, que eram locais onde os cursistas se reuniam para assistir às séries e interagir com os especialistas debatedores. As Secretarias Estaduais de Educação e o SESC Nacional foram os parceiros que nos estados se responsabilizaram pela implantação e o acompanhamento das telessalas. Nas Secretarias Regionais de Educação, o Programa TV Escola/Salto para o Futuro, faz parte dos NTEs - Núcleos de Tecnologias Educacionais. Em 1995, o Salto para o Futuro foi incorporado à TV Escola (canal educativo da Secretaria de Educação a Distância do Ministério da Educação SEED/MEC).

Com o intuito de melhorar a qualidade do ensino, valorizar e aperfeiçoar os professores da rede pública, assim como enriquecer o processo de ensino-aprendizagem, o MEC lançou, em 4 de setembro de 1995, o programa TV Escola, um canal televisivo do MEC, via satélite, destinado exclusivamente à educação, que passou a operar definitivamente em 4 de março 1996. De acordo com Toschi (2001, p. 91), a TV Escola consiste em um programa do MEC e da Presidência da República para a formação continuada de professores, sendo compreendido "[...] como um projeto capaz de 
'treinar' e apoiar o professor em sala de aula, a fim de melhorar a qualidade de ensino no Brasil." Uma das metas do programa - atualizar professores do ensino Fundamental e Médio - é cumprida no próprio local de trabalho, visto que os programas devem ser gravados, com a finalidade de serem vistos pelos professores em atividades extraclasse. No ar 24 horas por dia, a iniciativa é dividida em faixas, tais como Educação Infantil, Ensinos Fundamental e Médio, Salto para o Futuro e Escola Aberta. Duarte (2001) ressalta que, apesar de o objetivo principal dos programas TV Escola ser a formação continuada de professores, juntamente com a sua utilização como recurso didático, os programas apresentam concomitantemente outros temas de extrema relevância para os profissionais da educação, tais como a discussão dos Parâmetros Curriculares Nacionais, que, a partir de 1997, passaram a fazer parte dos eixos temáticos da programação.

Em 1997, a SEED/MEC, o Fundo de Fortalecimento da Educação (FUNDESCOLA), os estados e municípios propuseram, mediante celebração de parcerias, o desenvolvimento do Programa Proformação (MEC, 2009), voltado para a habilitação de professores sem a titulação mínima legalmente exigida, especialmente os professores que exercem atividades docentes nas séries iniciais, classes de alfabetização do Ensino Fundamental, ou Educação de Jovens e Adultos - EJA, como estratégia para melhorar o desempenho do sistema de Educação Fundamental em todas as regiões do país, contribuindo, assim, para a melhoria do processo ensino-aprendizagem e do desempenho escolar dos alunos nas redes estaduais e municipais do Brasil. O Proformação iniciou sua oferta nas regiões Norte, Nordeste e Centro-Oeste. Mas o MEC, a partir de 2004, passou a oferecer o programa para todas as regiões do país, funcionando na modalidade de $\mathrm{EaD} \mathrm{e}$ utilizando-se de materiais autoinstrucionais (impressos e vídeos) especificamente produzidos para o curso, atividades individuais e coletivas, e um serviço de apoio à aprendizagem realizado pela equipe de professores formadores das Agências Formadoras e por tutores. No caso dos vídeos, estes integram os conteúdos estudados nas áreas temáticas, incluindo situações de prática pedagógica e propostas de atividades diretamente ligadas à prática docente.

Em 1999, o Ministério da Educação (MEC) implementou o programa $P C N$ em Ação (MEC, 1999), desenvolvido em parceria com as secretarias municipais e estaduais de educação. De acordo com Prado (2000), esse programa teve como objetivo o desenvolvimento de programas de formação continuada no interior das escolas, incentivando o estudo em grupo dos Parâmetros e Referenciais Curriculares. Para isso, o projeto organizou-se em módulos de estudo compostos por atividades diferenciadas, que procuraram levar à reflexão sobre as experiências desenvolvidas nas escolas e acrescentar elementos que pudessem aprimorá-las. O material se organizava em textos, filmes e programas em vídeo, que podiam, além de ampliar o universo de conhecimento dos participantes, ajudar a elaborar propostas de trabalho com os colegas de grupo e realizá-las com seus alunos. No caso dos vídeos, serviam como parte do desenvolvimento dos módulos, como instrumento de potencialização das discussões do grupo, devendo ser assistidos com antecedência pelo coordenador do programa e utilizadas somente as partes relacionadas ao módulo e respectivo tema de discussão. Alguns vídeos da TV Escola foram sugeridos, assim como filmes disponibilizados comercialmente. 
No ano de 2001, o Profa - Programa de Formação de Professores Alfabetizadores (MEC, 2001), formulado pela Secretaria de Educação Fundamental do MEC, foi implementado por meio de cooperação técnica com as secretarias de educação estaduais e municipais e outras instituições que apresentassem tal interesse. $\mathrm{O}$ público-alvo do programa eram os professores alfabetizadores, isto é, professores que ensinam a ler e escrever na Educação Infantil e nas séries iniciais do ensino fundamental e na Educação de Jovens e Adultos. A proposta tinha o intuito de mobilizar os professores alfabetizadores para a necessidade de inovar o seu fazer pedagógico, a partir da apropriação de novos conceitos sobre o ensino e a aprendizagem da leitura e da escrita. Assim, segundo Menezes e Santos (2002), o Profa levou em conta a nova concepção de que, para o aluno aprender a ler e escrever de forma adequada à especificidade de cada interação, é necessário que ele participe de situações que o façam refletir, inferir, estabelecer relações e compreender informações, transformando-a em conhecimento próprio. O Profa se desenvolveu com base em materiais impressos e vídeos, sendo estes partes integrantes das unidades e preparados para serem assistidos na íntegra pelos cursistas, devendo, no entanto, serem estudados prévia e atentamente pelos coordenadores dos grupos de participantes. Os programas apresentavam cenas sobre os processos de ensino e aprendizagem, tendo sido gravadas em salas de aula de escolas selecionadas, com professores e estudantes reais.

Em 2002, o MEC lança o programa Parâmetros em Ação - Meio Ambiente na Escola (MEC, 2002), cujos objetivos e metodologias se vinculam ao PCNs em Ação, embora diferindo do Programa Parâmetros em Ação pela diversificação de materiais que oferecia. O programa era destinado aos professores de $5^{\mathrm{a}}$ a $8^{\mathrm{a}}$ séries do Ensino Fundamental e procurava, em consonância com a Política Nacional de Educação Ambiental (Lei $n^{\circ}$ 9795/99), efetivar a presença da educação ambiental nas políticas públicas dos sistemas de ensino. Segundo Mendonça (2004), o intuito era fazer provocações sobre temas como: sustentabilidade, biodiversidade, relação entre natureza e sociedade, dentre outros. A metodologia buscava mostrar diferentes visões sobre um mesmo assunto através de artigos, vídeos e atividades pedagógicas. Entre os materiais de apoio ao programa estavam: CD de música, CD-ROM de legislação ambiental, catálogos com publicações, sites e vídeos selecionados da TV Escola e de produtoras independentes.

Por último, cabe-nos apresentar o programa Pró-Letramento: mobilização pela qualidade da educação (MEC, 2007), o qual também se situa dentre os programas destinados à formação continuada de professores, visando à melhoria da qualidade de aprendizagem da leitura/escrita e matemática nos anos/séries iniciais do ensino fundamental. O programa propõe situações que incentivem a reflexão e a construção do conhecimento como processo contínuo de formação docente e o desenvolvimento de conhecimentos que possibilitem a compreensão da matemática e da linguagem e seus processos de ensino e aprendizagem. O Pró-Letramento funciona na modalidade semipresencial. Para isso, utiliza material impresso e vídeos e conta com atividades presenciais e a distância, que serão acompanhadas por professores orientadores/ tutores. Os vídeos apresentam professores expondo os pressupostos teóricos do programa, situações de sala de aula que servirão de exemplo para o planejamento das atividades pelos professores cursistas, discussões sobre o tema em grupos de professores, enfim, os 
vídeos dão suporte para as atividades que serão desenvolvidas pelos grupos de participantes do programa.

Em todos os casos, é importante anotar que ainda que tais programas tenham representado iniciativas que proporcionaram formação continuada a professores vinculados a municípios em que o investimento em programas desta natureza é reduzido e descontinuado (ALFERES, 2009), eles não nos parecem suficientes para pensar a formação continuada do professor, principalmente pela dificuldade em contemplar questões locais e específicas que dizem respeito à realidade diária do professor.

Ao analisar especificamente o Pró-Letramento, Santos (2008 apud ALFERES, 2009, p. 43) aponta que programas dessa natureza ainda se apóiam sobre a lógica de uma formação que "sempre se refaz, que começa do zero" e toma como pressuposto o fato de que todos os professores enfrentam os mesmos problemas, os quais fazem jus às mesmas respostas, como se, em educação, todas as realidades fossem iguais e pudessem ser contempladas da mesma forma. Nesse sentido, a autora realça que "A adoção de um modelo único de formação [...] parte do princípio que os professores não são suficientemente aptos para escolher propostas que mais incorporam suas necessidades." (SANTOS, 2008 apud ALFERES, 2009, p. 43). Projetos dessa natureza, ainda que tragam contribuições positivas para se refletir sobre o ensino e aprendizagem da língua portuguesa, falham ao deixar de contemplar a heterogeneidade dos docentes que atendem e ao não permitir que esses escolham e construam percursos formativos que possam fazer sentido na realidade em que atuam e no âmbito de seu desenvolvimento profissional em particular.

\section{CONSIDERAÇÕES FINAIS}

A análise da trajetória dos diferentes programas de $\mathrm{EaD}$ que utilizam videoaulas, delineada neste artigo, permite entrever algumas questões bastante importantes que procuraremos resumir ao longo desta seção.

Nenhum programa de EaD se efetiva desconectado de um contexto mais amplo que se vincula ao panorama educacional brasileiro em seus diversos âmbitos, o que implica questões relativas à diversidade de contextos abarcados por qualquer projeto que tenha a ambição de se estender por todo o território nacional. Nesse sentido, todo projeto que desconsidere diferenças e particularidades dos diferentes grupos de cursistas, tende à generalização e à massificação.

Os programas de $\mathrm{EaD}$ em nível de primeiro e segundo grau de alcance nacional aqui mencionados têm como base prioritariamente o uso de material impresso e videoaulas. Tais videoaulas foram, ao longo do tempo, distanciando-se de um modelo de aula expositiva que marcou e ainda marca bastante a realidade educacional brasileira, buscando associar a teledramaturgia e recursos outros, como a reportagem, a entrevista, à voz do professor. Se, por um lado, esses recursos tornam as interações mais dinâmicas e mantêm um elo com o concreto, por outro lado, passam eles mesmos a mediar a relação do aluno com o conhecimento, levando o aluno a experimentar interações que desconhece e nem sempre reconhece. 
A trajetória realizada pelo programa Telecurso nos dá pistas de um grande movimento que parece vir ocorrendo na $\mathrm{EaD}$ de forma a torná-la mais conectada ao universo real de alunos e professores/tutores que participam do programa, oferecendo ao aluno a ancoragem em um espaço virtual que possa ser visitado, ocupado e reconhecido por ele, como um local de interações produtivas nas quais tenha a possibilidade de materializar seu discurso. Isso aponta na direção de entender hoje a EaD como uma modalidade de ensino multimeios que incorpora diferentes tecnologias, de modo a evitar $o$ isolacionismo do aluno e a artificialização dos contextos educacionais.

Os programas destinados à formação do professor parecem representar um desafio semelhante, a despeito da qualidade crescente dos programas desenvolvidos e da conexão com o espaço da sala de aula, que parece constituir uma preocupação de programas como o Pró-Letramento e o Profa, os quais levam o professor à discussão de experiências reais no contexto da escola/turma. Esses programas ainda se apresentam como um universo destacado do universo de atuação do professor, dadas as condições em que se encontra o sistema de ensino brasileiro e dadas as próprias limitações relativas aos tempos-espaços destinados à formação continuada. Todavia, é importante perceber que tais programas não representam uma resposta direta aos anseios dos professores e não pressupõe, em muitos casos, um diálogo produtivo com os profissionais da educação. Isso potencializa a responsabilidade de agentes de formação e tutores que precisam demonstrar sensibilidade às particularidades de cada grupo específico.

\section{REFERÊNCIAS}

ALFERES, Maria Aparecida. Formação continuada de professores alfabetizadores: uma análise crítica do programa Pró-Letramento. Dissertação, Programa de Pós-graduação em Educação - Universidade Estadual de Ponta Grossa, Ponta Grossa (PR), 2009

BARROS, Daniela Melaré Vieira. Educação a distância e o universo do trabalho. Bauru, SP: EDUSC, 2003.

DUARTE, Eleuza Ferreira. O uso do programa TV Escola nas escolas da rede municipal de ensino de Dourados-MS. Dissertação, Programa de Pós-graduação em Engenharia de Produção - Universidade Federal de Santa Catarina, Florianópolis, 2001.

MACIEL, Leandro Silva Katzer Resende. Curso supletivo "A conquista": a história da teleducação matemática na década de 1970. . Rio de Janeiro, 2008a. Disponível em: $<$ http://www.sbemrj.com.br/spemrj6/artigos.htm $>$. Acesso em 05 de novembro de 2009.

Projeto "João da Silva"- pioneirismo em teleducação matemática. Anais online IV Colóquio de História e Tecnologia no Ensino da Matemática. Rio de Janeiro, 2008b. Disponível em: <http://www.limc.ufrj.br/htem4/papers/6.pdf. $>$. Acesso em 05 de novembro de 2009.

MENDONÇA, Patrícia Ramos. Avaliação dos Parâmetros em Ação - Meio Ambiente na Escola: um programa de Educação Ambiental do Ministério da Educação. In. : Anais 
do II Encontro da ANPPAS, 2004. Disponível em: $<$ http://www.anppas.org.br/encontro_anual/encontro2/GT/GT10/patricia_mendo\%E7a.pdf $>$. Acesso em 20 de fevereiro de 2010.

MENEZES, Ebenezer Takuno de; SANTOS, Thais Helena dos. Profa (Programa de Formação de Professores Alfabetizadores). In: Dicionário Interativo da Educação Brasileira - EducaBrasil. São Paulo: Midiamix Editora, 2002.

MINISTÉRIO DA EDUCAÇÃO. Salto para o futuro. Disponível em: http://portal.mec.gov.br/index.php?option $=$ com content\&view $=$ article\&id=13258:saltopara-o-futuro\&catid=111:tv-escola. Acesso em 20 de novembro de 2009.

. SECRETARIA DE EDUCAÇÃO BÁSICA (SEB)/ SECRETARIA DE EDUCAÇÃO A DISTÂNCIA (SEED). Pró-letramento: programa de formação continuada de professores de anos/séries iniciais de ensino fundamental. Brasília: MEC, 2007.

- SECRETARIA DE EDUCAÇÃO. SECRETARIA DE EDUCAÇÃO FUNDAMENTAL. Parâmetros em ação: programa de desenvolvimento profissional continuado. Brasília: A Secretaria, 1999.

SECRETARIA DE EDUCAÇÃO FUNDAMENTAL. Coordenação-Geral de Educação Ambiental. Parâmetros em ação: meio ambiente na escola. Brasília: MEC, 2002.

SECRETARIA DE EDUCAÇÃO A DISTÂNCIA. Programa de formação de professores em exercício - Proformação. Disponível em: http://proformacao.proinfo.mec.gov.br/. Acesso em: 25/ 11/ 2009.

SECRETARIA DE EDUCAÇÃO FUNDAMENTAL. Programa de Formação de Professores Alfabetizadores. Brasília: MEC, 2001.

MOORE, Michael; KEARSLEY, Greg. Educação a distância: uma visão integrada. Trad. Roberto Galman. São Paulo: Cengage Learning, 2008.

MORAN, José Manuel. Aperfeiçoando os modelos de EAD existentes na formação de professores. Educação. Porto Alegre, v. 32, n. 3, set./dez. 2009. p. 286-290.

MOREIRA, João Flávio de Castro. Os telecursos da Rede Globo: a mídia televisiva no sistema de educação a distância (1978-1998). 2006.181 p. Dissertação (Mestrado). Programa de Pós-Graduação em História, Instituto de Ciência Humanas, Universidade de Brasília, Brasília, 2006.

PRETTO, Nelson de Lucca. Desafios para a educação na era da informação: o presencial, a distância, as mesmas políticas e o de sempre. In: BARRETO, R. G. (org.). Tecnologias educacionais e educação a distância: avaliando políticas e práticas. Rio de janeiro: Quartet, 2001. p.29-53. 
TOSCHI, Mirza Seabra. TV Escola: o lugar dos professores na política de formação docente. In: BARRETO, R. G. (org.). Tecnologias educacionais e educação a distância: avaliando políticas e práticas. Rio de janeiro: Quartet, 2001. p. 85-104.

VIGOTSKI, L. S. A formação social da mente. São Paulo: Martins Fontes, 2008. 